\title{
CORPORATE MODELS \\ MODELLEN VAN EEN ORGANISATIE
}

\author{
door Prof. Dr. A. Bosman en Drs. B. V. H. van de Kieft
}

\section{Inleiding}

Sedert het eind van de jaren zestig is het aantal artikelen en boeken waarin aan. dacht wordt geschonken aan het verschijnsel "corporate model” gestaag toegenomen. Wij zullen voor een dergelijk model de term organisatiemodel (OM) hanteren. Voor het ontstaan en de groei in de belangstelling van het verschijnsel $O M$ is een aantal oorzaken aan te wijzen. Wij noemen o.a.:

a. de toenemende behoefte aan het systematiseren en formaliseren van de beslissingsprocessen binnen organisaties;

b. de beperkingen die de optimalisatie benadering van de neoklassieke onderne. mingstheorie, de doelvariabelen benadering van Tinbergen en de in de bedrijfseconomie gehanteerde axiomatische benadering hebben ten aanzien van het be schrijven van het handelen en het verklaren van het gedrag van organisaties (zie Naylor (21));

c. het in vele gevallen bij praktische toepassing falen van OR modellen (zie Little (18)).

In dit artikel zullen wij in paragraaf 3 een overzicht van de literatuur op het gebied van OM geven. Aan de hand van dit overzicht zullen we enkele punten onderscheiden die bij de opzet en de constructie van een OM veelal een centrale plaats innemen. In paragraaf 4 noemen we enkele voordelen en beperkingen van het gebruik van OM. In paragraaf 5 trekken we enkele conclusies vooral t.a.v. het verdere onderzoek van OM. Voor we met onze beschouwing over OM beginnen, zullen we in paragraaf 2 een aantal begrippen definiëren die we in dit artikel re. gelmatig gebruiken. Voor de lezers die zich verder in het onderwerp willen ver. diepen, hebben we een uitvoerige literatuurlijst opgenomen.

\section{Enkele begrippen}

Onder een organisatie verstaan wij elk samenstel van produktiefactoren, dat ge zamenlijk het bereiken van één of meer doelstellingen nastreeft. Om deze doel stellingen te bereiken zullen activiteiten moeten worden uitgevoerd. De middelen beschikbaar en nodig voor het uitvoeren van deze activiteiten zijn schaars. Bij het toewijzen van die middelen ontstaat een keuzeprobleem. Het proces van beslissen binnen de organisatie, dat de keuze van de uit te voeren activiteiten bepaalt, noemen wij het handelen van de organisatie. De uit dit proces resulterende beslissin gen wordt het gedrag van de organisatie genoemd.

Een organisatie is een reëel systeem, d.w.z. het is een verzameling van zintuigelijk waarneembare elementen en relaties tussen deze elementen. Deze relaties bepalen de structuur van het systeem. Een OM kan worden beschouwd als een afbeel. ding van een organisatie of van een deel ervan in de vorm van een ideëel of abstract systeem. Een dergelijk systeem is een symbolisch model van het reële systeem, de organisatie.

Een abstract systeem kan op verschillende manieren worden geconstrueerd. 
Bij deze constructie wordt altijd gebruik gemaakt van variabelen. Wij onderscheiden de volgende groepen van variabelen.

a. De endogene of uitkomstvariabelen, deze beschrijven de uitkomst van een proces. Deze uitkomst wordt bepaald door:

b. De exogene - omgevings - variabelen. Dit zijn de variabelen die de endogene beïnvloeden, maar omgekeerd door de endogene zelf niet worden beïnvloed. De beslisser kan de waarde van de omgevingsvariabelen zelf niet beïnvloeden.

c. De exogene - instrumentele - variabelen, hiervan kan de waarde wel door de beslisser, althans binnen bepaalde grenzen, zelf worden bepaald.

$d$. De doelvariabelen, dit kan de gewenste waarde van een endogene variabele zijn, de zgn. Tinbergen benadering, maar ook de waarde van een doelstellings. functie. Deze waarde wordt meestal bepaald door de som van produkten van endogene en instrumentele variabelen. De instrumentele variabelen zijn dan de parameters in de waardefunctie.

\section{De inhoud van het begrip OM}

Bij het bestuderen van de literatuur op het gebied van OM blijkt dat er diverse, nog al verschillende, meningen bestaan over de opzet, de inhoud en het doel van een OM. De volgende drie citaten illustreren dit.

a. Rosenkranz (26) stelt: „In the sequel a corporate simulation and planning model will be understood to be description of a complete firm and its development or activity in time and at different locations. This description is achieved by the specification, estimation, and solution of equations to reproduce and predict the behaviour of a firm in the areas of finance, production, and marketing, assuming different environments and courses of action".

b. Hamilton en Moses (15) schrijven: "The system presented in this paper is a specialized, computer.based management information system with extensive analytical capabilities. Its power derives from the integration of diverse but complementary planning models with user-oriented information storage and handling features". c. Grinyer en Wooller (12) geven als omschrijving: „Corporate models are sets of conventional, logical and mathematical expressions that represent the key operations of the company and in virtually all cases include the items entering the nor. mal profit and loss account and balance sheet".')

We zullen de uit de literatuur bekende OM trachten te classificeren aan de hand van de volgende punten.

1. Wat zijn de uitgangspunten, c.q. doelstellingen, bij het opstellen van het model.

2. Welke onderzoektechnieken gebruikt men bij het opstellen van een model.

3. Welke delen van de organisatie zijn in het model opgenomen.

4. Welke meta-theorie of welk paradigma wordt gehanteerd bij het opstellen van een model.

Op een aantal plaatsen zullen wij in hetgeen volgt gebruik maken van de resultaten van een onderzoek dat Naylor en Schauland (22) in 1974 hebben verricht. In de V.S., Canada en Europa werden 1881 bedrijven geënquêteerd, die of een $\mathrm{OM}$ in een of andere vorm gebruikten, doende waren een $\mathrm{OM}$ te ontwikkelen

\footnotetext{
1) De cursivering in de drie citaten is van deze schrijvers.
} 
of het plan hadden opgevat een OM te gaan vervaardigen. Van de 346 bedrijven die op de enquête hebben gereageerd, gebruikten of ontwikkelden 250 een OM. $\mathrm{Bij}$ de bestudering van de resultaten van dit onderzoek moet men rekening houden met het feit, dat Naylor en Schauland zich niet hebben bezig gehouden met de zogenaamde „non-response”. Bovendien geven zij geen duidelijke omschrij. ving van het object van het onderzoek, in casu het OM. Voor andere soortgelijke onderzoeken verwijzen wij naar Gershefski (9), Grinyer en Wooller (12), Mans (19) en Eppink e.a. (7). Onderlinge vergelijking van deze onderzoeken wordt bemoeilijkt door het feit dat ook bij de laatst genoemde schrijvers een duidelijke omschrij. ving van het begrip OM ontbreekt.

1. De doelstelling die men met het opstellen van OM nastreeft kan worden omschreven als het gebruik van een abstract systeem als hulpmiddel voor het ne. men van beslissingen in organisaties. Deze doelstelling kan men op verschillende manieren trachten te realiseren. De abstracte systemen die men gebruikt kunnen in twee groepen worden onderverdeeld.

a. De abstracte systemen voor de beslissingsvoorbereiding, dit zijn systemen waarmee de beslisser kan experimenteren in het kader van de te nemen beslissingen. Rosenkranz (25) onderscheidt twee typen.

1. De "what-if” experimenten, gegeven bepaalde waarden van de parameters, functionele relaties en waarden van omgevingsvariabelen kan het systeem de waarde van de endogene variabelen berekenen als functie van de exogene va. riabelen en de tijd. Instrumentele variabelen ontbreken bij dit type.

2. De "if-then" experimenten, in dit geval worden aan de modelspecificatie van de ,what-if" experimenten instrumentele en doelvariabelen toegevoegd.

De abstracte systemen van de klasse al en a2 hebben doorgaans als kenmerk dat voor de beschrijving van de bestaande situatie wordt gebruik gemaakt van de econometrische methode, zie punt 2. De „what-if” en „if-then” experimenten liggen dan in elkaars verlengde. Bij de eerste wordt nagegaan wat er zal gebeuren met de endogene variabelen als bepaalde omgevingsvariabelen veranderen. $\mathrm{Bij}$ de tweede tracht men m.b.v. instrumentele variabelen eventuele niet gewenste veranderingen in de endogene variabelen t.g.v. wijzigingen in de omgevingsva. riabelen op te vangen. Aan de twee door Rosenkranz genoemde typen zouden wij een derde willen toevoegen.

3. De "then-else" experimenten, de daarbij gebruikte abstracte systemen worden ontleend aan de bedrijfseconomie (management science) en het operationele on. derzoek. De nadruk ligt veelal op het definiëren en het specificeren van alterna. tieven waaruit m.b.v. doelvariabelen kan worden gekozen. Aan de problematiek van het bepalen van de relevante exogene variabelen en de daarbij behorende waarde der parameters wordt bij dit laatste type over het algemeen veel minder aandacht geschonken dan bij de eerste twee.

b. Abstracte systemen voor het omschrijven en het eventueel uitvoeren van be. slissingsprocessen en de daarvoor noodzakelijke gegevensverwerking. Met deze groepen van systemen worden geen experimenten uitgevoerd. Deze groep kan in twee subgroepen worden onderverdeeld.

1. De systemen die worden gebruikt voor het nemen van routinebeslissingen, bijv. die voor de voorraadregulering per artikel. 
2. De systemen, c.q. programma's, die worden gebruikt voor:

- het verwerken van gegevens,

- het berekenen van bepaalde uitkomsten, zoals het schatten van parameters,

- het op efficiënte wijze invoeren, bewaren en verkrijgen van gegevens.

Deze programma's worden veelal niet aangeduid met de naam systemen, ze zijn echter wel een belangrijk onderdeel van elk OM en vaak van doorslaggevend belang voor het gebruik dat van een OM kan worden gemaakt.

2. In aansluiting op het behandelde onderscheid kunnen de volgende typen van abstracte systemen worden onderscheiden. Voor a 1 en a2 het uit de econometrie bekende systeem van differentievergelijkingen.

$$
f_{\mathrm{t}}\left(y_{\mathrm{t}}, y_{\mathrm{t}-1}, x_{\mathrm{t}}, u_{\mathrm{t}}, e_{\mathrm{t}}\right)=0
$$

waarin: $y=$ een vector met endogene variabelen,

$x=$ een vector met omgevingsvariabelen,

$u=$ een vector met instrumentele variabelen,

$e=$ een vector met storingstermen.

Een lineaire representatie van [1] met $m$ vergelijkingen en $n$ tijdsperioden geeft:

$$
\text { A. } x_{\mathrm{t}}+\mathrm{B} \cdot y_{\mathrm{t}}+\mathrm{B} 1 \cdot y_{\mathrm{t}-1}+\mathrm{C} \cdot u_{\mathrm{t}}+d_{t}=u_{\mathrm{t}}
$$

waarin: $\mathrm{A}, \mathrm{B}, \mathrm{Bl}$ en $\mathrm{C}=$ matrices met parameters, $d_{\mathrm{t}}=$ een vector met constanten.

Aan [2] kan bijv. in de benadering van Theil (29) een waardefunctie worden toe. gevoegd.

De systemen in de categorie a3 kunnen van geheel verschillende vorm zijn.') Een voorbeeld is een systeem dat m.b.v. lineaire programmering wordt opgelost.

$$
\begin{aligned}
& \mathrm{A} \cdot y \leqslant x \\
& \mathrm{z}=u \cdot y \longrightarrow \max
\end{aligned}
$$

De symbolen $y$ en $x$ hebben dezelfde betekenis als in [1] en [2]. De matrix A wordt in een dergelijk geval meestal de matrix met technische coëfficiënten genoemd. Deze coëfficiënten worden m.b.v. eenvoudige schattingsprocedures vastgesteld. Door het niet gebonden zijn aan de complexe schattingsprocedures uit de econometrie is het aantal graden van vrijheid waarover de opsteller van het systeem beschikt bij [3] veel groter dan bij [1] en [2].

$\mathrm{Bij}$ de constructie van systemen onder punt 1 genoemd onder b staat veelal de constructie en de beschikbaarheid van programmatuur centraal. Voor zover er

\footnotetext{
7) Er kunnen bepaalde overgangsgebieden van enerzijds al en a2 en anderzijds a3 worden onderscheiden. Een van de be kendste van deze overgangsgebieden is dat van de zgn. lineaire beslissingsregels, Holt cs. (1) 7). Het nadeel van de methoden die bij al en a2 worden gebruikt, tot deze methoden moeten ook die van de zgn. systeem dynamica worden gerekend, is dat ze het beschrijven van de bestaande of in het verleden bestaande situatic centraal stellen en weinig of geen aandacht besteden aan het genereren van alternatieven waaruit bij het beslissen kin worden gekozen.
} 
abstracte systemen bestaan voor het nemen van beslissingen blijkt de relevantie ervan voor het beslissen doorgaans voor een zeer groot deel te worden bepaald door het kunnen beschikken over de juiste gegevens op het juiste moment. Dit juist blijkt veel meer afhankelijk te zijn van de capaciteiten van het gegevensver. werkingssysteem dan van de inhoud van de beslissingsprocedure, Bosman (1). We zullen de mogelijke inhoud van deze benadering aan de hand van twee voorbeel. den toelichten.

i. De benadering van Boulden en Buffa (4). Deze aanpak is erop gericht om bin. nen een kort tijdsbestek te komen tot een OM, dat interaktief via terminals kan worden gebruikt voor ondersteuning van beslissingen. Zij gaan uit van een zgn. General System Program, dat kan worden opgevat als een verzameling procedu. res, die zijn opgeslagen in het geheugen van een computer en waarmee zowel interne als externe gegevens kunnen worden geanalyseerd, voorspellingen kun. nen worden gedaan, simulaties kunnen worden uitgevoerd en waarmee uitvoer kan worden verzorgd. Door het General System Program, dat voor alle toepassingen gelijk is, te koppelen aan de in de organisatie aanwezig veronderstelde data base en te verbinden met wat Boulden en Buffa het Corporate Model Logic noemen, is men in staat snel en op eenvoudige wijze een OM te construeren en te implementeren. In het Corporate Model Logic worden de relevant geachte grootheden en relaties tussen de grootheden uit de organisatie afgebeeld. Het Corporate Model Logic is evenals de data base uniek voor elke organisatie. Boulden en Buffa geven geen methode voor de constructie van het Corporate Model Logic. ${ }^{3}$ ) ii. De benadering van Hamilton en Moses (15). In de aanpak van beide auteurs kan OM in 5 subsystemen worden opgesplitst (zie figuur 1).

1. Informatie subsysteem, dit gedeelte van het OM verzorgt de verwerking, het transport en de opslag van gegevens.

2. Optimalisatie subsysteem, dit subsysteem maximaliseert de „resultaten” van de organisatie over een meer perioden planning horizon door de juiste alternatieven te kiezen voor de produktie en de financiering. Voor een gedetail. leerde beschrijving van het gebruikte gemengd.geheeltallig lineair program. meringsmodel, zie Hamilton en Moses (14).

3. Simulatie subsysteem, m.b.v. dit subsysteem kan een simulatie worden uitgevoerd voor een gegeven verzameling alternatieven en voor gegeven waarden van de exogene variabelen en de parameters om de gevolgen voor een aantal financiële grootheden door te rekenen.

4. Econometrisch subsysteem, dit subsysteem is ontworpen om inzicht te ver. schaffen in de ontwikkeling van macro economische grootheden en die van bedrijfstakken waarin de organisatie actief is of van plan is activiteiten te ontplooien.

5. Risico-analyse subsysteem, met dit subsysteem kan informatie worden verkre. gen over de mogelijke gevolgen van variaties in waarden van bepaalde pa. rameters.

\footnotetext{
3) Zie voor een verdere uitwerking Boulden (3).
} 
In onderstaande figuur wordt de onderlinge samenhang tussen de 5 subsystemen weergegeven.

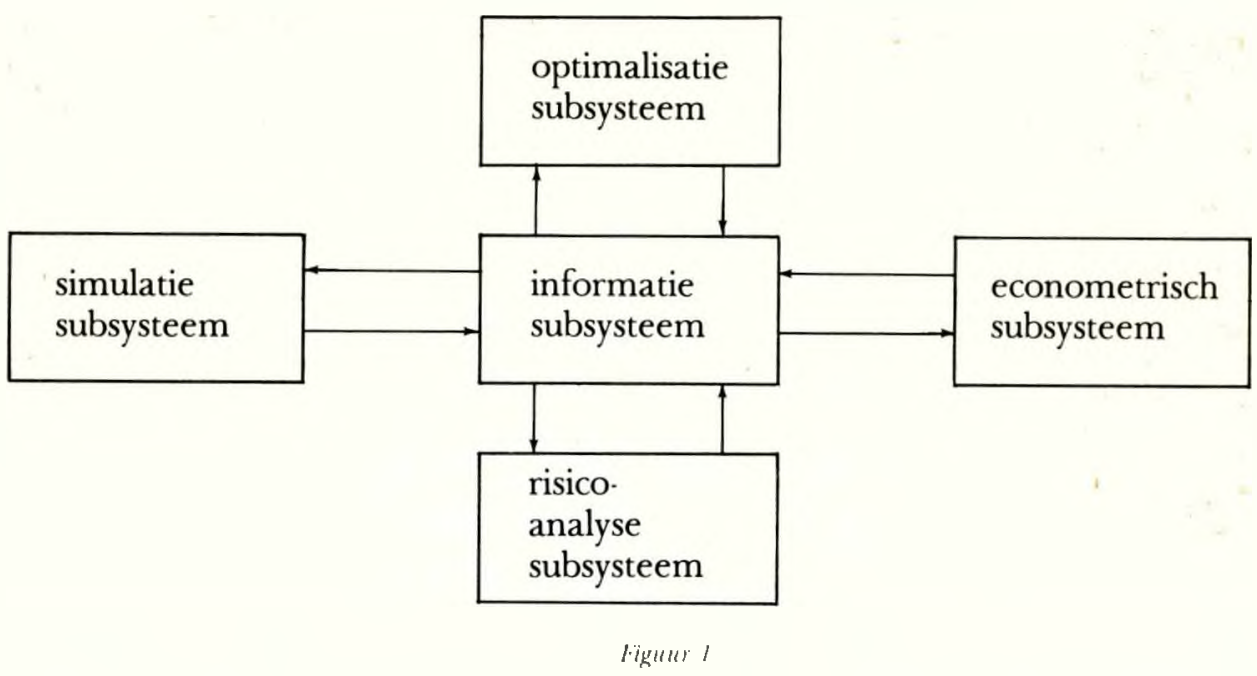

Hamilton en Moses geven van de inhoud van deze subsystemen een tamelijk uit. voerige beschrijving en vermelden hoe in hun specifieke geval deze inhoud tot stand is gekomen. Duidelijker dan bij Boulden en Buffa blijkt de benadering van Hamilton en Moses een poging de beide onder punt $l$ onderscheiden groepen te integreren.

Naast de gebruikte onderzoektechnieken kunnen de volgende kenmerken van OM worden onderscheiden.

I. De structuur van de organisatie wordt bij de meeste OM op een vaste, niet fle. xibele wijze afgebeeld. Dit houdt in, dat de mogelijkheid van structuurverande ring in de organisatie niet als graad van vrijheid wordt meegenomen. Enkele auteurs doen dit wel. Rosenkranz (26) bijvoorbeeld maakt een onderscheid tussen zgn. conjunctieve relaties en niet conjunctieve relaties. De eerste hebben een vas te vorm in de loop van de tijd, de tweede kunnen qua vorm in de loop van de tijd veranderen. Om dit te realiseren stelt Rosenkranz voor gebruik te maken van dummy variabelen, ongelijkheden en logische variabelen.

II. De grootheid tijd speelt een belangrijke rol. Men kan deze grootheid zowel discreet als continu opvatten. In alle door ons in de literatuur gevonden OM wordt de tijd beschouwd als een discrete grootheid en wordt de lengte van de tijdsintervallen voor elk interval gelijk genomen. In $45 \%$ van de modellen werd met een periodelengte van één jaar gewerkt (Naylor en Schauland), in 5\% van de gevallen was de periodelengte een kwartaal, in $14 \%$ van de modellen een maand en in $33 \%$ een combinatie van deze mogelijkheden. De gemiddelde lengte van de planning horizon bleek acht jaar te bedragen.

III. Uit het onderzoek van Naylor en Schauland blijkt dat $94 \%$ van de OM alleen deterministische en slechts $6 \%$ stochastische variabelen bevatten. Dit vindt zijn oorzaak o.a. in het feit, dat het gebruik van stochastische variabelen in een model dikwijls het doorrekenen tot een ingewikkelde en in elk geval tijdrovende procedure maakt. 
IV. Voor het uitvoeren van experimenten met een OM wordt vrijwel in alle ge vallen gebruik gemaakt van de mogelijkheden van de hedendaagse computer. Daarvoor is het noodzakelijk dat het OM wordt vertaald in een computertaal. FORTRAN blijkt uit het onderzoek van Naylor en Schauland veruit favoriet. In $50 \%$ van de gevallen werd deze programmeertaal gebruikt. Opmerkelijk en de belangrijke rol van de computer als hulpmiddel onderstrepend is dat $26 \%$ van de modellen gebruik maakten van programmeertalen, die speciaal zijn ontworpen voor het ontwikkelen en programmeren van OM. Gezien het belang van de on der punt 1 genoemde toepassingen a3 en b mag worden verwacht dat dit percentage in de toekomst nog wel zal stijgen. Overigens moet worden opgemerkt dat vele fabrikanten van computers de laatste jaren veel aandacht schenken aan het ontwikkelen van de noodzakelijke softwarepakketten voor het gebruik van OM. Andere programmeertalen die gebruikt werden zijn COBOL, PLl, APL, DY. NAMO en Assemblers. In $62 \%$ van de gevallen was het mogelijk op enigerlei wijze interactief met het OM te werken.

3. De vraag welke delen van een organisatie in een OM zijn opgenomen kan op verschillende manieren worden beantwoord. We zullen twee criteria gebruiken om een antwoord te vinden.

a. Welke functies in een organisatie worden in een OM afgebeeld? Naylor en Schauland vinden in hun steekproef dat $80 \%$ van de bedrijven de financiële functie in een model had gepresenteerd. Bij $41 \%$ van de bedrijven die een OM gebruiken waren marketing activiteiten in het OM opgenomen en bij $39 \%$ was de produktie op de een of andere wijze in het model afgebeeld. Bovendien waren althans een deel van de relaties tussen de organisatie en zijn omgeving veelal ex. pliciet in het OM opgenomen. Dit laatste is in overeenstemming met een andere uitkomst van het onderzoek van beide auteurs, nl. dat $76 \%$ van de OM konden worden gebruikt voor het uitvoeren van „what-if” en ,if-then” experimenten. $b$. Op welk niveau of welke niveaus van de organisatie heeft een OM in het al. gemeen betrekking? De vraag kan worden beantwoord door de aggregatiegraad van de in het abstracte systeem opgenomen variabelen te beschouwen. Immers men mag aannemen dat er een relatie zal bestaan tussen de grootte van de ag. gregatiegraad en de plaats van het niveau in de organisatiestructuur. Bij een or. ganisatie waar alle beslissingen in de top van de organisatie worden genomen en de lagere niveaus alleen worden gebruikt voor de uitvoering van die beslissingen zal men een zgn. top-down benadering rolgen bij de constructie van een OM als hulpmiddel bij het beslissingsproces. Bij een top-down aanpak begint men met het beschouwen, analyseren en beschrijven van de gehele organisatie op het hoogste niveau in de organisatie on vervolgens op lagere niveaus subsystemen te gaan onderscheiden tot men een mate van ,gedetailleerdheid" heeft verkregen, die de constructeur en de gebruikers van het model bevredigt. In het algemeen zal men daarbij gebruik maken van geaggregeerde variabelen. De aggregatie vindt door gaans plaats m.b.v. prijzen en over produktgroepen. Bij een bottom-up benadering, daarentegen, worden eerst de lagere niveaus in de organisatie uitvoerig bestudeerd en beschreven en worden vervolgens de variabelen voor een beschouwing op een hoger niveau bepaald m.b.v. aggregatieprocedures en de gegevens van de lagere niveaus. Uit het onderzoek van Gershefski (9) blijkt dat $65 \%$ van de sy. stemen volgens de top.down benadering en $35 \%$ volgens de bottom-up benade. 
ring tot stand zijn gekomen. Grinyer en Batt (11) vinden in hun literatuuronder. zoek 16 top-down en 18 bottom-up systemen. Aangezien top-down en bottom-up) dikwijls verschillend wordt gedefinieerd, zijn beide uitkomsten niet direct verge. lijkbaar. Wij zijn van mening dat OM vooral betrekking hebben op de beslissingsproblematiek zoals die zich voordoet op de hogere niveaus in de organisatie. structuur. De abstracte systemen die op de lagere niveaus worden gebruikt, zou. den wij, ook gezien onze voorgaande beschouwingen onder de punten $/$ en 2 niet tot de klasse OM willen rekenen.

4. Wij zouden drie groepen van opstellers van OM willen onderscheiden aan de hand van de paradigma's of meta-theorieën die ze gebruiken.')

I. Het econometrische paradigma leidt tot het gebruik van abstracte systemen zoals geschetst in |1] en [2]. In het algemeen zal het toepassingsgebied de top van de organisatie zijn en liggen de toepassingsmogelijkheden, zoals reeds is opge. merkt, in de „what-if" en ",if-then” experimenten. De ontwikkelde abstracte systemen besteden vooral aandacht aan de relaties met de omgeving. Het bestuderen van het proces van beslissen kan onderontwikkeld worden genoemd. Voor een deel is dit een gevolg van het ontbreken van een theorie over het beslissen die hypothesen levert waarop de econometrische methode kan aansluiten. Zoals dan kan worden verwacht volstaan de auteurs in deze groep met het geven van richtlijnen die bij de constructie in acht moeten worden genomen of het noemen van een aantal eigenschappen die een OM moet hebben om goed in een organisatie te functioneren en als hulpmiddel bij het nemen van beslissingen te dienen. Deze zijn dan doorgaans meer gebaseerd op persoonlijke ervaringen met de constructie van een OM dan op een theorie over de constructie van een OM.

Little (18) stelt bijvoorbeeld de volgende eisen:

- Het model moet eenvoudig zijn.

- Het model moet robuust zijn, d.w.z. het moet lastig zijn voor de gebruiker om het model "vreemde" uitkomsten te laten genereren.

- Het model moet gemakkelijk te hanteren zijn.

- Het model moet snel aan veranderende omstandigheden kunnen worden aan gepast.

- Het model moet op alle belangrijke punten volledig zijn.

- Het model moet op eenvoudige wijze toegankelijk zijn voor de gebruiker en de resultaten moeten in een voor hem begrijpelijke vorm worden weergegeven. Voor meer van dergelijke adviezen en richtlijnen zie Grinyer en Batt (11), Dick. son e.a. (6) en Brown (5). Alhoewel de door Little genoemde eisen op zich duidelijk zijn, is het ook zeker dat aan een aantal ervan niet simultaan kan worden voldaan. Eerst in samenhang met een theoretische fundering kunnen dan voor strijdige eisen oplossingen worden gevonden.

II. Het ontbreken van een theoretische constructie bij het gebruik van de eco. nometrische methode zou kunnen worden opgevangen door een beroep te doen op de bedrijfseconomie. De bedrijfseconomie zou, evenals dit in de macro eco nomie is gebeurd, de hypothesen voor het toepassen van de econometrische me thode moeten leveren. De bedrijfseconomie in Europa heeft echter, enkele uit zonderingsgevallen buiten beschouwing gelaten, haar axiomatische benadering

Zie voor een methodologische beschouwing over de relevantic van een paradigma of meta theorie. Bosman (2). 
van beslissingsproblemen niet losgelaten. Alhoewel een axiomatische benade ring van problemen en het gebruik van econometrische methoden elkaar niet di. rect uitsluiten, moet toch worden geconstateerd dat een directe aansluiting doorgaans niet voor de hand ligt. Het gat dat daardoor, methodologisch gezien, ontstaat, wordt in het geval van de OM gevuld door gebruik te maken van technie. ken uit bijv. het operationele onderzoek. Wij hebben deze benadering geschetst met de benaming constructie van het abstracte systeem |3|. Kenmerkend voor deze systemen is:

- de nadruk die wordt gelegd op het algoritme en het functioneren van het vereiste informatiesysteem;

- het uitvoeren van ,then else" experimenten;

- de geringe belangstelling voor de relaties met de omgeving;

- de validatie van het abstracte systeem.

Voor de auteurs die tot deze groep behoren kunnen we concluderen dat de techniek(en) ontbreken om een aansluiting te vinden tussen de hypothesen uit de axiomatische theorieconstructies en de onderzoekmethoden om deze op grond van waarnemingen uit de empirie van een inhoud te voorzien.

III. Het ontbreken van de onder II genoemde technieken tracht men de laatste jaren vooral op te vangen door een beroep te doen op de systeemtheorie. Ter voorkoming van misverstanden wijzen wij er uitdrukkelijk op dat dit beroep in vele gevallen ten onrechte wordt gedaan. Dat geldt in al die gevallen waarin de systeemtheorie wordt gebruikt als een techniek voor het schatten van relaties de zgn. systeemidentificatie. Wij zijn dan weer beland bij de auteurs van groep I. Een voorbeeld in Nederland is het door Hanken en Reuver (16) beschreven in. tegraal bedrijfsmodel dat, naar onze mening, als een OM kan worden beschouwd. Uit hun publicatie wordt niet duidelijk waarom het abstract systeem zo is opgebouwd. Zij besteden daaraan ook geen aandacht. Hun publicatie handelt over het schatten van de parameters van hypothesen, niet over de inhoud ervan. Indien men de systeemtheorie gebruikt voor het opstellen van theorieën, in Nederland wordt dit meestal de systeembenadering genoemd, dan kan men resultaten verwachten die de genoemde strijdigheid geheel of gedeeltelijk opvangen. Deze weg is echter lang en vereist een theorieconstructie die op een aantal punten nog al afwijkt van de gebruikelijke, Bosman (1). Rosenkranz kan als één van de weinige auteurs worden beschouwd die deze weg is ingeslagen.

Wij willen deze paragraaf afsluiten met een enkele opmerking over de implementatie van OM. Dickson e.a. (6) citeren de uitspraak van McKenney ,an unused model, no matter how elegant, is a failure". Om dit falen te voorkomen willen veel auteurs reeds in het beginstadium de uiteindelijke gebruikers actief betrek. ken bij het project, dat tot de realisatie van een OM moet leiden. Van belang is het om de doelstellingen van de gebruikers en de verwachtingen die zij hebben t.a.v. het $\mathrm{OM}$ te kennen. Een groot aantal schrijvers acht de ondersteuning en goedkeuring van het project door het topmanagement een noodzakelijke voorwaarde voor het welslagen ervan. Een ander belangrijk punt is dat het systeem in zijn eerste opzet dient aan te sluiten bij de bestaande planningprocedures zoals die in de organisatie worden gehanteerd (Grinyer en Batt (11), Brown (5)). Bovendien moeten de uitkomsten van het systeem aan de gebruiker worden gepresenteerd in een vorm waarmee hij vertrouwd is. Wanneer het systeem is voltooid, 
althans een eerste versie gereed is voor gebruik, dan moet een goede documentatie worden vervaardigd. De gebruiker zal op de hoogte moeten worden gebracht van de mogelijkheden en beperkingen van het OM.

\section{Voordelen en beperkingen van $O M$}

In deze paragraaf willen wij in het kort een aantal voordelen en een aantal be perkingen van het gebruik van OM noemen. Wij baseren ons wederom op de uit komsten van het onderzoek van Naylor en Schauland (22). Als de belangrijkste po. sitieve punten van het gebruik van een OM zagen de geënqueteerde bedrijven: - de mogelijkheid om meer alternatieven te onderzoeken;

- betere kwaliteit van de beslissingen;

- meer effectieve wijze van plannen;

- beter inzicht verkrijgen in de organisatie;

- sneller tot stand komen van beslissingen.

Slechts $4 \%$ van de bedrijven ondervonden geen voordeel van het gebruik van een OM. Dit lage cijfer kan wellicht worden verklaard uit het feit dat Naylor en Schauland, zoals wij al eerder opmerkten, geen nader onderzoek hebben gedaan naar de non-response.

Naast deze voordelen werden o.a. de volgende bezwaren naar voren gebracht:

- onvoldoende flexibiliteit van het systeem;

- slechte documentatie over het systeem;

- te veel invoergegevens nodig;

- het ontwikkelen van het systeem duurde te lang.

Ook Goldie (10) noemt deze nadelen. Bovendien vermeldt deze schrijver ver. schillende oorzaken van het gebrek aan vertrouwen dat gebruikers van een OM in de uitkomsten hebben:

- het systeem is nog niet geheel voltooid, maar er wordt steeds gezegd dat dit spoedig wel het geval zal zijn;

- het systeem kan dikwijls niet worden uitgelegd zonder gebruik te maken van voor de gebruiker onbegrijpelijke technische termen;

- de organisatie die in het OM is afgebeeld verandert sneller dan het systeem kan worden veranderd;

- er worden geen betrouwbaarheidsgrenzen voor de uitkomsten van het systeem gegeven.

De genoemde nadelen zijn voor een belangrijk deel enerzijds een gevolg van het ontbreken van een adequate theorie en anderzijds ontstaan ze door de bij het ontbreken van die theorie optredende strijdigheden bij het voldoen aan de uit de techniek voortvloeiende eisen.

\section{Conclusies}

Uit het voorgaande zal het duidelijk zijn dat wij als belangrijkste oorzaak voor de spraak - en begripsverwarring rond OM beschouwen het ontbreken van een adequate theorie over het beslissingsproces op de hoogste niveaus van organisaties. Onderzoek naar OM zal aan dit punt niet voorbij kunnen gaan en het zal ten minste een meta-theorie moeten formuleren om een basis te vinden voor de constructie van hypothesen. Zoals wij reeds opmerkten kan de systeembenadering 
daarbij wellich de helpende hand bieden. Naast onderzoek naar de theoriecon structie kan ook onderzoek worden uitgevoerd naar een groot aantal punten ran min of meer technische aard. Zonder te streven nareen uitputtende lijst ran onderwerpen, noemen we de volgende:

a. verbetering van de projectorganisatie bij het construesen van een OM:

b. verbetering van het informatiesysteem voor een OM, daarbij kan men o.a. denken aan de volgende onderwerpen:')

- data base management,

- het beschikbaar stellen van algoritmen voor het schatten van de vorm van de relaties, de parameters en de ralidatie van de uitkomsten,

- het ontwikkelen van algoritmen voor het uitvoeren van experimenten.

- het ontwikkelen van algoritmen voor hel uitvoeren van gevoeligheidsanalyses,

- het ontwikkelen van invoer. en geëigende uitvoerprogramma's;

c. het verbeteren van de ,verkoopbaarheid" van een OM;

d. het verbeteren van de mogelijkheden om OM te valideren.

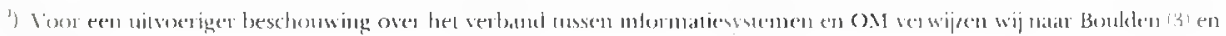
S.akmall 27 


\section{Literatuur}

(1) Bosman, A., Systemen, planning netwerken, Leiden, H. E. Stenfert Kroese B.V., 1969.

(2) Bosman, A., Een mela-theorie ouer hel gedrag wan urganisaties, verschijnt binnenkont.

(3) Boulden, J. B., Compuler-assisted Planning Systems, New York, McGraw.Hill Book Company, 1975.

(4) Boulden, J. B., E. S. Buffa, Corporate Models: On Line Real-Time Systems, /Iaruard Business Review, Vol. 48 , no. 4 (juli-aug. 1970 ).

(5) Brown, D. E., Stages in the Cycle of a Corporate Planning Model, zie Schrieber (28).

(6) Dickson, G. W. J. J. Muriel, J. C. Anderson. Computer Assisted Planning Models: a Functional Analysis, zic Srhrietser (28).

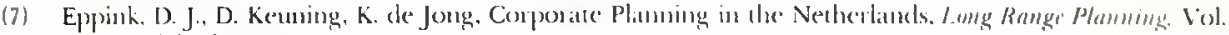
9. no. 5 (oktober 1976).

(8) Gershefski, G. W., Building a Corporate Financial Model. Irarvard Business Revuez, Vol. 47, no. 4 (juli-aug. 1969).

(9) Gershefski, G. W., Corporate Models the state of the art, zie Schrieber (28).

(10) Goldie, J. H., Simulation and Irritation, zie Schricber (28).

(11) Grinyer, P. H., Ch. D. Batt, Some tentative findings on corporate financial simulation models. Operational Research Quarterly, Vol. 25, no. 1 (maart 1974).

(12) Grinyer, P. H., J. Wooller, Computer models for corporate planning, Long Range Planning Vol. 8. no. I (februari 1975).

(13) Grochla, E. N., N. Szyperski (eds), Modell- und Computer gestiulzte Unternehmungsplanung, Wiesbaden, Be. triebswirtschaftliche Verlag Th. Gabler, 1973.

(14) Hamilton, W. F., M. A. Moses, An optimization model for corporate financial planning, Operations Research Vol. 22, no. 3 (mei.juni 1973).

(15) Hamilton, W. F., M. A. Moses, A computer-based corporate planning system, hanagement Science, Vol. 21, no. 2 (oktober 1974).

(16) Hanken, A. F. G., H. A. Reuver, Inleiding tot de systeemleer, Leiden, H. E. Stenfert Kroese B.V., 1973.

(17) Holt, C. C., F. Modigliani, J. F. Muth. H. A. Simon, Planning Production Inventories and Work Force, Englewood Cliffs, Prentice.Hall, Inc, 1960.

(18) Little. J. D. Models and Managers: The concept of a decisions calculas, Managemene Science. Vol. 16. no. 8 (ap)iil 1970).

(19) Mans, G.. Stand und Entwicklung von Planungssystemen in Unternehunungen der B.R.D., zie Grochlat en Szyperski (13).

(20) Meyhak, H., Formalised long range planning in the firm with simulation models, zie (23).

(21) Naylor, Th. H., Towards a theory of corporate simulation models, zie (23).

(22) Naylor, Th. H., H. Schauland, A survey of users of corporate planning models, Management Science, Vol. 22, no. 9 (mei 1976).

(23) Proceedings conference, Compuler simulation versus analytical solutions for business and economic models, W. Goldberg (ed.), Gotenburg, 1973.

(24) Rosenkranz, F., Methodological concepts of corporate models, zie (23).

(25) Rosenkanz, F., Status and Future Use of Corporate Planning and Simulition Moslels: Case Sindies and Conclusions. Computergestutale Unternehmungsplanung, Sungant. Science Research Associates, 1976.

(26) Rosenkranz, F., S. Pellegrini, Corporate modeiling: Methodology and computer based model design procedure. Angewande Informatik-Applied Informatics, no. 6. 1976.

(27) Sackman, H., Advanced Research in Online Planning, Online Planning, eds. H. Sackman, R. L. Citrenbatun. Fnglewood Clifts, Premice Hall. Inc. 1972.

(28) Schrieber, A. N. (ed.) Corporate Simulation Model. Seatte, University of Washington Press, 1970.

(29) Theil, H., Economic Forecasts and Policy, Amsterdam. North Holland Publ., 1961. 